\title{
Research on the innovation of logistics management in the electronic commerce
}

\author{
Liyan Zuo ${ }^{1, a}$, Changliang $\mathrm{Li}^{2, \mathrm{~b}}$ \\ ${ }^{1}$ Department of industry and business administration, Daqing Vocational College, Daqing 163000 \\ China; \\ 2 Oilfield Special Products Manufacturing Branch, Daqing Petroleum Equipment Group, Daqing \\ 163000 China \\ azuoliyan82@126.com; ' lichang1982@126.com
}

Keywords: Innovation; Logistics management; E-commerce

\begin{abstract}
Recently, the electronic commerce (E-commerce) is an important economic trade way for the logistics management. The modern e-commerce technology has greatly affected on the traditional logistics. And the modern logistics will develop to the trend of informatization, networking and functionalization with the development of the e-commerce. In this paper, the innovation of logistics management was discussed in detail. The results indicated that the government guidance and industrial legislation should be gradually strengthen, and the transformation of logistic organizational structure should be accelerated. Besides, we should learn from other advanced countries to improve the planning and control system of e-commerce logistic activities. And we should pay more attention to the cultivation of talented people. In addition, we should give more support to the development of logistics finance, and we should accelerate the build of e-payment platform.
\end{abstract}

\section{Introduction}

With the advances in Internet technology, e-commerce continues to flourish, traditional enterprise management and logistics management models suffered a great challenge [1, 2]. Most enterprises follow the trend, registered their own web site, developed a corresponding network development plan, and gradually establish a network business systems. Logistics as the third largest source after raw material resources sectors and human resources sectors, it provides a strong support for the continuous development of e-commerce. At the same time, e-commerce has brought opportunities for the development and improvement of the current logistic model [3]. Generally speaking, our country long-term economic development, "emphasis on production, light circulation", the low efficiency of the whole society logistic, high logistics costs, China's logistics costs to GDP ratio of nearly 18\% under market economy conditions in the national circulation economy status and role of awareness is not enough. Logistics management is to achieve the lowest cost of logistics to meet customer requirements for the purpose of logistics activities appropriate planning, organization, coordination and control, that is logistic management of raw materials, semi-finished and finished materials such as the outer flow within the enterprise plan the whole process carried out, implementation, control and other activities [4, 5].

\section{Problems of logistics management in e-commerce environment}

\section{The smaller scale of logistics enterprises.}

In recent years, our country was founded nearly 800000 logistics enterprises, the number has already been a certain scale, but small and medium enterprises still account for the vast majority, the proportion of large-scale logistics enterprise is very small. These SMEs exist generally management scale smaller, management level relatively backward, single function, value-added services weak, the lack of advanced technical support and a series of deficiencies

${ }^{1}$ Corresponding author: Liyan Zuo (1973-), female, Acheng County, Heilongjiang Province, E-mail: zuoliyan82@126.com 


\section{Shortage of logistics management professionals.}

With the rapid development of the world economy, and constantly improve the level of modern technology, the logistics industry is considered the driving force of economic development. However, logistics management personnel shortage has become one of the obstacles of the logistics industry, it is an important cause of lower logistics enterprise service levels. Age of electronic commerce, logistics management major needs macro-level management personnel, logistics management personnel and logistics management personnel. Complex logistics personnel who is familiar with the knowledge field of modern economy and trade, logistics operations, transport, English and international trade, it has a very important role in modern logistics development.

\section{E-commerce logistics and distribution system is not perfect.}

The majority of technology and equipment and management tools in our logistics enterprises are relatively backward, network services and information system is not perfect, many logistics enterprises have yet to achieve online job, still use the original transmission of information and control methods. Information flow is mainly built on the basis of written, we can not provide timely logistics information for customers, which not only reduces the level of logistics services, but also inhibited the development of China's logistics industry, affecting the promotion and application of e-commerce, it becomes a constraint development bottleneck for logistics and e-commerce.

The emphasis of government and enterprises on logistics and e-commerce is not enough.

The competition mechanism and regulations of e-commerce logistics market are not perfect, there is no uniform law on the entry and exit, and competition rules in the market. For the lack of effective restraint mechanism in social commerce logistics, leading to severe unfair competition. Logistics development involves many aspects of infrastructure, technology and equipment, industrial policy, investment and financing, these areas belong to different government departments management. As the relevant functional departments lack sufficient knowledge of modern logistics, also lack a unified and coordinated strategic thinking, logistics marketing and industry management were artificially by sector, region and industry division, resulting in a fragmentation of logistics management and redundant construction and other issues.

\section{Basic approach of innovation in Electronic Commerce Logistics Management}

\section{Gradually strengthen government guidance and industry legislation.}

Our e-commerce logistics has just started, it is not perfect in all aspects, mature e-commerce logistics system has not been established, the relevant laws and regulations are not perfect, it is very unfavorable for the development of modern logistics. Governments should support the development of e-commerce logistics enterprises in policy and funding, make the right policies and industry development strategies, to strengthen the development of e-commerce network security technology research, and laws and regulations. For example, as soon as make the development of logistics information technology standards and information resources standards, establish mechanisms for exchange and sharing of logistics information collection, processing and services; build e-commerce logistics distribution system to promote e-commerce logistics industry vigorous development; actively promote enterprise logistics management information, and promote extensive application of information technology, and guide enterprises to increase investment in e-commerce logistics industry; scientific and reasonable construct logistics infrastructure, to establish China's logistics entities network, lay a good foundation for the development of the logistics industry; promote regional logistics information platform construction, to encourage inter-city logistics platform for information sharing; accelerate the industry logistics public information platform and build a national highway transportation information networks and information systems as well as air cargo public transport and other services mode; effectively integrate the suppliers flow, logistics, capital flow and information flow, form the country and the global market trading platform.

As the e-commerce policy and legislative policies from different departments, bull management, low overall efficiency, it is difficult to solve the major problems existing in the development of e-commerce, recommended to develop "e-commerce promotion law" as soon as possible, and make it the fundamental law of China's e-commerce development, to solve bull ruling, effectively 
regulate the online trading market, protect the lawful conduct e-commerce, promote e-commerce and the national economy faster and better development.

Speed up the logistics organizational structure changes, combine the information technology and advanced management concepts.

To combine the informatization and advanced management concepts, create intelligent logistics. For example, For example, electronic warehouse management system fundamentally achieve a first-in first-out management, to address the manual ledger queries slow, error-prone and other defects; transportation and distribution management system will optimize vehicle loading, select transportation route, ensure that the right goods at the right time and place of delivery to the customer. Also, the use of advanced foreign management practices, such as zero inventory (that is, to provide the necessary amount of product in the necessary time) and so on. Future competition is the supply chain, not just a concept of logistics, but how to move products from manufacturers to consumers, how to achieve the quickest, most efficient and lowest-cost competition.

Experiences of developed countries, and improve planning and control system of e-commerce logistics activities.

The United States has the Internet-based logistics information platform, with mature standardized logistics software, integrated logistics information with information technology, develop logistics solutions to optimize all stages of the logistics process, so that make the logistics management more scientific, standardized, rapid and accurate operation, to improve increased efficiency and effectiveness. For example, Wal-Mart through the flow of information to integrate and optimize and timely processing the logistics and capital flow, achieve effective logistics cost control. Therefore, in order to achieve innovative logistics management, logistics enterprises in China must adhere to the "for customer service" as the center of this basic principle, the quality of service and customer needs into first place. This requires enterprises develop strategic plannings for logistics activities according to market flexibility and customer orientation, and anticipate problems that may arise, to take preventive measures in advance. During the logistics planning and implementation process, it should be based on performance goals for internal and external logistics activities to make reasonable monitor, adjust the deviation between the desired goals and the implementation of the results.

\section{Focus on training e-commerce and logistics management professionals.}

Learning the introduction of modern logistics management philosophy and management style, which is designed to quickly reverse the backwardness of the low domestic transport market transport capacity, low efficiency, low service level. First, strictly managed on the qualifications of logistics services enterprises; second, in order to medium-sized transport enterprises led, market-oriented, leading transport enterprises to embark on large-scale, intensive, professional operation road, so that decentralized management small logistics enterprises gradually on the right track, take the large-scale development road, lay the foundation for modern logistics information management; and finally, to break the regional boundaries, the establishment of a national service network to form a highly efficient, timely and accurate logistics information network.

Speed up the construction of electronic payment platform.

We should accelerate the development of "People's Republic of China Electronic Payment Law", made clear that the legislative purpose, definition of electronic payment, electronic payment types the regulatory authorities, electronic payment subject, approval and certification the central bank should be introduced for third-party payment institutions innovation guideline as soon as possible, to encourage and guide the correct payment business innovation; to encourage payment agencies with good business, risk control ability firstly try third-party pilot innovative services, reduce the approval process; to support commercial banks and other financial institutions and third-party payment agencies to strengthen innovative cooperation.

\section{Conclusion}

Recently, the modern e-commerce technology has greatly affected on the traditional logistics. Therefore, the innovation of logistics management should be carried out. In this paper, the 
government guidance and industrial legislation should be gradually strengthen, and the transformation of logistic organizational structure should be accelerated. Besides, we should learn from other advanced countries to improve the planning and control system of e-commerce logistic activities. And we should pay more attention to the cultivation of talented people. In addition, we should give more support to the development of logistics finance, and we should accelerate the build of e-payment platform.

\section{References}

[1] W. Lu. The relationship between modern supply chain management and logistics management [J]. Coastal Enterprises and Technology, 2006, vol. 3, pp. 12-15.

[2] Y. Tao. Current situation and thinking of SMEs in logistics management [J]. Enterprise economy, 2011, vol. 1, pp. 58-60.

[3] Q. Zheng. Logistics management and the method of realizing modernization [J]. China Cement, 2002, vol.7, pp. 45-49.

[4] X.L. Wang, H.J. Li. Research on the logistics cost and control [J]. Logistics Technology, 2006, vol. 3, pp. 21-25.

[5] F.S. Meng. The influence of network environment on Logistics Management [J]. Logistics Technology, 2014, vol. 7, pp. 33-37. 